\title{
PARA ALÉM DAS METODOLOGIAS PRESCRITIVAS NA EDUCAÇÃO FÍSICA: A POSSIBILIDADE DA CAPOEIRA COMO COMPLEXO TEMÁTICO NO CURRÍCULO DE FORMAÇÃO PROFISSIONAL
}

\author{
José Luiz Cirqueira FalCÃo*
}

\section{RESUMO}

Este artigo tem por objetivo criticar o caráter alienador das denominadas "metodologias prescritivas" no campo da Educação Física brasileira e apresenta, como referência e contraponto, aspectos do desenvolvimento da capoeira e a possibilidade de trato com esse conhecimento a partir da noção de complexo temático.

PALAVRAS-CHAVE: educação - educação física - capoeira - prática pedagógica - trato com o conhecimento.

\section{INTRODUÇÃO}

escassez de propostas metodológicas de caráter crítico e a sofisticação teórica pautada pela utilização de discursos idealistas e abstratos, dificilmente entendidos pelos professores, desencadeiam uma confusão conceitual no interior dos currículos de Educação Física instaurando um fosso entre a produção teórica e a realidade vivida por significativa parcela de profissionais da área.

Segundo Cunha (1997) e Moreira (1999), existe uma crise de legitimação da concepção crítica de currículo por não se conseguir, na prática, implementar seus princípios teóricos. Embora os avanços teóricos angariem muito prestígio no meio acadêmico, as discussões travadas dificilmente chegam à escola.

* Doutor em Educação, Professor Adjunto do Departamento de Educação Física da Universidade Federal de Santa Catarina, Pesquisador efetivo do Colégio Brasileiro de Ciências do Esporte, Coordenador do Núcleo de Estudos Capoeira e Sociedade, da Universidade Federal de Santa Catarina, Integrante da Linha de Estudo e Pesquisa em Educação Física \& Esporte e Lazer da Faculdade de Educação da Universidade Federal da Bahia e Integrante do Núcleo de Estudos Pedagógicos em Educação Física do departamento de Educação Física da Universidade Federal da Santa Catarina. 
É com ênfase na "centralidade da prática", conforme aponta Moreira (1999, p. 30), e em comunhão "com os que nela atuam", sem perder de vista a idéia do todo, que é possível promover avanços teóricometodológicos. A organização do trabalho pedagógico, centrada na prática, deve superar procedimentos autoritários, fragmentados, verticalizados, cartesianos, e acolher a horizontalidade, a pluralidade, o contexto. Não há mais lugar para as pedagogias de assimilação, prescritivas, através das quais o estudante vai à escola ou universidade, aprender representações, conceitos e conteúdos previamente determinados pelo professor.

Essas considerações teóricas são oportunas para refletirmos sobre a necessidade de tratarmos os aspectos metodológicos no campo da Educação Física a partir de uma concepção crítica de currículo e, com isso, qualificar os processos de intervenção pedagógica no interior da área, mediante a superação de metodologias prescritivas ainda bastante presentes.

Nossas formulações são decorrentes de uma experiência investigativa realizada no ano $2002 \mathrm{com}$ a temática Capoeira no Curso de Graduação em Educação Física da Universidade Federal de Santa Catarina (UFSC), a partir da estratégia metodológica da pesquisa-ação.

\section{O TRATO COM O CONHECIMENTO DA CAPOEIRA COMO COMPLEXO TEMÁTICO}

Para qualificar o conceito complexo temático capoeirano, problematizamos as principais iniciativas de trato com esse conhecimento que conquistaram maior visibilidade ao longo do desenvolvimento histórico desta manifestação cultural. A partir daí, utilizamo-nos da noção de "sistema dos complexos", formulada pelo educador russo M. Pistrak (1888 - 1940), na obra Fundamentos da Escola do Trabalho, que, apesar de ter sido escrita em 1924, continua bastante atual, embora distorcida por algumas concepções idealistas de educação. Pistrak (1981) defendia dois grandes fundamentos para a pedagogia socialista soviética: as relações da escola com a realidade e a auto-organização dos estudantes. Ao criar o sistema dos complexos, o referido autor propugnava a organização do ensino através de temas socialmente significativos, por meio dos quais, os estudantes compreendiam a dinâmica e as relações existentes entre aspectos diferentes de uma mesma realidade. 
Esse arranjo, tornado possível a partir da articulação do conceito de complexo temático com a manifestação cultural capoeira, possibilitou-nos levantar subsídios para o trato com o conhecimento no currículo de formação profissional.

\section{AS PROPOSTAS METODOLÓGICAS PARA O ENSINO DA CAPOEIRA}

No final do século XIX, começaram a aparecer as primeiras propostas metodológicas para o ensino da capoeira. Antes, aprendia-se "de oitiva", como dizia Mestre Bimba. Ou seja, os capoeiras encontravamse e jogavam capoeira sem a preocupação de ensinar ou aprender, embora aprendiam e ensinavam, educavam e educavam-se, mas de forma assistemática, não intencional.

A primeira referência histórica relacionada com a metodologização da capoeira foi a de Mello Moraes Filho, que na década de 1890, já sinalizava com a possibilidade desta manifestação se transformar em esporte nacional. Como integrante das elites brancas da virada do século XX, Moraes Filho (1979, p. 257) utilizou-se de alguns argumentos realçados de positividade: a capoeira era esporte, era mestiça e era nacional. Para justificar seus postulados, distorceu praticamente todas as características dessa manifestação, construiu um "passado glorioso" para a mesma, e destituiu o que ela tinha de "mal e bárbaro". Ao fazer uma espécie de assepsia da capoeira, camuflando suas contradições históricas, o referido autor acena com metodologias prescritivas e apresenta os primeiros rudimentos metodológicos para tratar formalmente esse conhecimento.

Em 1907, aparece o opúsculo intitulado Guia do Capoeira ou Gymnastica Brazileira, cujo autor teria julgado prudente não revelar seu nome, pelos preconceitos existentes em relação à capoeiragem, mencionando apenas a sigla O.D.C., que significava Ofereço, Dedico e Consagro à distinta mocidade. Esse opúsculo defendia a sistematização da capoeira como um método nacional de ginástica. O opúsculo enaltecia os capoeiras de outrora pela riqueza de seus variados movimentos, pela prudência e por serem "amigos da ordem". Alertava, ainda, que a "degeneração lenta e succesiva" começava a destruir "as bellezas desta gymnastica pátria pela ausência dos últimos notáveis mestres (sic)" (O.D.C., 1907, p. 2). Eis, aqui, mais um exemplo de deturpação e distorção 
do legado cultural da capoeira, com vistas a tratá-la pedagogicamente, a partir de metodologias prescritivas.

Em 1928, o escritor Coelho Neto (1928) publicou o artigo "Nosso Jogo", no qual apresenta uma proposta de inclusão da capoeira nas escolas civis e militares, chamando a atenção para a excelência desta como ginástica e estratégia de defesa individual. No mesmo ano, Aníbal Burlamaqui, um oficial da Marinha do Rio de Janeiro, publica o livro Ginástica nacional (capoeiragem): methodisada e regrada, no qual apresenta regras para o jogo esportivo da capoeira. Esta obra é apresentada com certo ufanismo à sociedade da época, como um "grito de brasilidade", como possibilidade de libertação da influência dos "sports estrangeiros" e para destruir o "archaico e tolo preconceito de que a 'GYMNASTICA BRASILEIRA' - a capoeiragem - desdoura a quem a pratica" (sic!) (BURLAMAQUI, 1928, p. 9). Segundo o prefaciador da obra, Mario Santos, trata-se de um livro "modesto, prático e útil", que apresenta regras esportivas para tornar um "gymnasta brasileiro" capaz de vencer os de outras lutas estrangeiras. Ao defender a capoeira, Burlamaqui o fazia sob o argumento de que ela era superior ao boxe, à luta romana e à luta japonesa, pois reunia elementos de todas elas e ainda estava associada à "inteligência e à vivacidade peculiares ao tropicalismo dos nossos sentimentos" (BURLAMAQUI, 1928, p. 5).

Essas propostas metodológicas para o ensino da capoeira expressavam uma concepção elitista de educação e estavam sintonizadas com os códigos nacionalistas, higienizadores e eugênicos que hegemonicamente impregnavam as propostas e os programas para a educação brasileira do final do século XIX e início do século XX.

Apesar de essas propostas prescritivas expressarem os desejos de segmentos das elites da época, elas não foram amplamente difundidas, nem tampouco, efetivamente implementadas e acolhidas pelas escassas instituições de ensino de então.

Na primeira metade do século XX, Mestre Bimba leva a capoeira para recintos fechados. Nestes espaços Bimba metodizou um sistema de sequiências de movimentos de capoeira e criou uma série de procedimentos didáticos, dentre eles, exame de admissão ${ }^{1}$, curso de especialização, emboscadas, o "esquenta banho" 2 , a "cintura desprezada" , cerimônias de batismo e graduação, sistema de hierarquia com graduações, formaturas, que caracterizaram o que se tornou 
mundialmente conhecido como Capoeira Regional. A maior parte dos discípulos era constituída de acadêmicos dos cursos de Medicina, Direito e Engenharia, da antiga Universidade da Bahia. Segundo Vieira (1995), a Capoeira Regional insere-se numa lógica metódica e racional do mundo com vistas ao incremento da eficiência, em oposição ao que ele chamou de "ética da malandragem", subjacente à Capoeira Angola.

A Capoeira Angola, tal como a Regional, também foi construída como identidade de projeto, a partir de um movimento de ruptura entre praticantes de capoeira, na cidade de Salvador. Os "angoleiros", encabeçados por Mestre Pastinha, atacaram a Capoeira Regional acusandoa de ser descaracterizada e elegeram os rituais religiosos dos caboclos e do candomblé como a fonte em que deveriam beber. Ela foi escolhida pela intelectualidade baiana, como foi o caso de Jorge Amado e Edson Carneiro, como a capoeira verdadeira, a pura, a de raiz, embora boa parte de seus fundamentos tenha sido criada por mestres contemporâneos de Pastinha, como Mestre Waldemar e Mestre Canjiquinha.

Nas suas ações de organizador desta nova vertente, Pastinha buscou seletivamente, na tradição antiga, alguns conceitos que a emolduraram, como os de mandinga, malícia, brincadeira, religiosidade, que passaram a ser assumidos como componentes da tradição da Angola. Rompeu com as rodas violentas do passado que, para ele, serviam para a "promoção do horror". Chamou a atenção para a importância do ritmo, do ritual e do lúdico. Sistematizou expedientes para entrada e saída de jogo, "chamadas" e organizações de roda. "Para ele, a capoeira teria que ser dosada, demonstrada, mantida em seus segredos" (PIRES, 2002, p. 84).

É fato que existem opiniões que colocam a Capoeira Angola e a Regional em pólos diametralmente opostos, como podemos verificar na análise do historiador Edson Carneiro, quando, em 1937, disse que

O capoeira Bimba, virtuoso do berimbau, tornou-se famoso desde que, nos anos 30, criou uma escola em que tem treinado atletas no que apelidou de luta regional baiana, mistura de capoeira com jiu-jitsu, box e catch. A capoeira popular, folclórica, legado de Angola, pouco, quase nada tem a ver com a escola de Bimba (CARNEIRO, 1977, p. 14).

Se para Mestre Bimba, a capoeira surgiu na região do Recôncavo Baiano, daí Regional, portanto, brasileira, para Mestre Pastinha, ela teria sua origem em Angola, a partir de uma dança-luta de iniciação sexual 
chamada N'golo, portanto, africana. A partir dessas diferentes visões de seus principais líderes acerca da origem da capoeira, perfilam outras tantas tentativas de cisão que demarcaram profundamente os códigos simbólicos de uma e de outra.

Para Mestre Decanio, entretanto, os dois estilos mais consagrados da capoeira se complementam. Para ele, a Capoeira Angola (a dos outros) pode ter um apelo forte à tradição, que se traduz em africanidade, religiosidade, mandinga etc, mas a Regional (a dele) tem um apelo maior à eficiência corporal, que se traduz em performance, racionalidade, marcialidade. Para suavizar a oposição que engendra essas construções, principalmente em Salvador, Mestre Decanio afirma em tom de conciliação: "As duas isoladas não prestam. Uma completa a outra" (SANTANA, 2001, p. 5).

O debate/embate Capoeira Angola/Capoeira Regional tem contribuído significativamente para a afirmação de processos identitários no contex to capoeirano e tem sido sistematicamente analisado por sociólogos e historiadores. O que alimenta esse debate são questões de natureza estética, ritualística, simbólica e, a depender da região, ele se torna mais ou menos aguerrido. Muito raramente, ele gravita em torno de discussões e/ou ações voltadas para as condições materiais de vida, processos de dominação cultural, ou aspectos marcadamente políticos, como a clássica luta de classes.

O fato é que a capoeira constitui um complexo temático e no concreto vivido os discursos que alimentam essa manifestação vão para além de uma simples filiação a outro estilo. O recente livro Bimba, Pastinha e Besouro de Mangangá, publicado por Pires (2002), revela, de forma brilhante e esclarecedora, as contradições e os embates presentes nas propostas de invenção da capoeira contemporânea.

Outra proposta de pedagogização da capoeira foi a de Inezil Penna Marinho que publicou, em 1945, um trabalho relacionado com o seu trato metodológico, intitulado Subsídios para o estudo da Metodologia do Treinamento da Capoeiragem. Através deste estudo, Marinho tentou consolidar o projeto de criação de um método nacional de ginástica que tivesse por base a capoeira, seguindo a trilha de Burlamaqui. Esse autor almejava sistematizar a capoeira como uma ginástica brasileira, a exemplo da Ginástica Sueca, da Ginástica Francesa e da Ginástica Alemã (MARINHO, 1945). 
A partir de uma visão que restringia a concepção do ser humano a uma dimensão predominantemente biológica, que se aproximava da doutrina fascista, Marinho (1945) busca fundamentar o seu trabalho nas características fenotípicas do povo brasileiro e elege o "mulato" como o tipo ideal para a capoeira, pois considerava que ele era mais inteligente $\mathrm{e}$ menos bruto que o negro e teria mais destreza que o branco.

Os mulatos, geralmente menos corpulentos que os negros, menos sobrecarregados de músculos de força que o trabalho pesado desenvolvia, mais ágeis, mais flexíveis, mais elásticos, mais nervos do que músculos, representavam o tipo ideal do capoeira, pois a tais qualidades físicas somavam maior coragem, maior audácia, libertos que se encontravam do espírito de submissão arraigado à raça negra (MARINHO, 1945, p. 7).

Essas referências concretas dão o passo inicial e uma maior visibilidade ao processo de pedagogização da capoeira. Se, por um lado, as propostas de Moraes Filho, Coelho Neto, O.D.C., Aníbal Burlamaqui e Inezil Penna Marinho não adquiriram grandes repercussões no meio capoeirano, a famosa metodologia de Bimba e a engajada proposta de Pastinha ganharam os quatro cantos do mundo, embora em níveis distintos de inserção e divulgação.

\section{A NECESSIDADE DA CRÍTICA SISTEMÁTICA}

Essas referências históricas relacionadas à capoeira são fundamentais para ilustrar e explicitar a necessidade de uma crítica sistemática em relação a todo o conhecimento produzido e veiculado no interior das instituições acadêmicas. Podemos assegurar que os critérios de verdades, muitas vezes velados, devem ser explicitados e a história constitui-se, inegavelmente, num vigoroso pilar na busca dessa verdade e contribui para a construção de uma concepção crítica de trato com o conhecimento.

Com o advento do processo de escolarização da capoeira, esta manifestação adquire novos contornos pedagógicos e novos tratamentos metodológicos. Se antes, as propostas de pedagogização da capoeira eram galgadas em referências nacionalistas, chauvinistas, higienistas, ufanistas, etnicistas, essencialistas e esportivizantes, geralmente vinculadas a projetos pessoais de alguns expoentes dessa manifestação, nos últimos 
anos surgem novas possibilidades que ampliam as possibilidades de tratamento pedagógico em relação a esta manifestação cultural.

A despeito dessas novas possibilidades, respaldadas pelo estatuto científico, a capoeira é, hoje, hegemonicamente tratada na lógica do treinamento esportivo, nos mesmos moldes das diversas modalidades presentes na sociedade. Os chamados treinos contemplam, em geral, procedimentos extremamente simplistas, nos quais prevalecem o comando e a ênfase na performance física.

Nesta lógica, que privilegia o rendimento corporal, que molda e remodela o sujeito com vista ao aprimoramento individual, a disciplina é, freqüentemente, construída a partir de referenciais sedutores e vencedores, muito bem monitorados pela mídia.

O rendimento físico é garantido por séries extenuantes de exercícios aplicados com finalidades específicas, em que tudo pode (e deve) ser medido, classificado, comparado, definido. Essa exaustiva exploração da aptidão física subestima outras possibilidades para o trato com o conhecimento da capoeira, dentre elas, o componente lúdico, a diversão, enfim, os conhecimentos produzidos a partir de suas ricas referências culturais e históricas.

É fundamental compreender que, no trato com o conhecimento da capoeira, como no trato com qualquer outra cultura corporal, o sujeito deve ser concebido como uma unidade indivisível, que se expressa pela existência cultural, política, social, afetiva, emocional etc. Dada a impossibilidade concreta de uma divisão, pensar o sujeito é pensá-lo em sua totalidade. Daí não ser possível falar de rendimento corporal sem envolver outras dimensões da existência humana. Todas essas categorias fazem parte de um complexo amálgama que é a vida humana, una e plural, dialética, jamais fragmentada, como pretendem tratá-la algumas correntes pedagógicas, inclusive, como possibilidade de manipulação e dominação.

\section{CONSTRUINDO SUPERAÇÕES}

No calor das contradições, o movimento concreto da capoeira vem acenando que é possível construir referências mais sintonizadas com o desenvolvimento da sociedade atual na perspectiva de sua transformação. A despeito de barreiras políticas e econômicas, os capoeiras, através de suas práticas significativas, destroem fronteiras e edificam um mundo onde, simbolicamente, tudo são margens, onde não há centro, 
onde não há outros. Com isso, ela aponta novas perspectivas pedagógicas, em que os educadores são chamados a criar pedagogias sem fronteiras, capazes de incorporar os deslocamentos que aproximam as pessoas em torno de projetos solidários de construção da felicidade humana.

Diante dessa possibilidade, propugnamos que o trato com o conhecimento da capoeira no currículo de formação profissional deve ser capaz de explicitar os avanços e os retrocessos de uma prática cultural complexa. E que esse trato seja operado não na forma de prescrição, mas, principalmente, como produção e divulgação dos saberes construídos a partir de diferentes experiências.

Consideramos que o trato com esse conhecimento, bem como os demais componentes da chamada cultura corporal, deve contemplar o seu "acervo histórico-cultural" e não apenas se reduzir a "seqüências de treinamento físico" prescritas pelo mestre ou professor. Nesse sentido, torna-se premente "não desencarná-la do movimento cultural e político que a gerou" (COLETIVO DE AUTORES, 1992, p. 76), a fim de evitarmos que os nossos jovens se desenvolvam numa espécie de presente contínuo, alheios ao passado que os gerou, pois, independente de origens e histórias pessoais, são todos herdeiros de experiências e fatos históricos decisivos que consolidaram o presente exatamente como ele se apresenta (HOBSBAWM, 1995).

Segundo Hobsbawm (1995, p. 13), "a destruição do passado - ou melhor, dos mecanismos sociais que vinculam nossa experiência pessoal a das gerações passadas - é um dos fenômenos mais característicos e lúgubres do final do século XX". Sendo assim, para que a nossa experiência seja compreendida e explicada com radicalidade, rigorosidade e em sua totalidade, devemos levar em consideração os fatos históricos cruciais que contribuíram para o seu desenvolvimento e como eles se relacionam entre si para materializar a realidade tal como ela é.

Estas considerações podem contribuir para um tratamento pedagógico rigoroso, radical e de conjunto da capoeira, à medida que esta não deve ser interpretada como uma prática puramente mecânica, desconectada da realidade social, mas como um processo no qual se interpenetram dimensões históricas, afetivas, sociais e motoras, que jamais se tornam rotina.

$\mathrm{O}$ trato com o conhecimento da capoeira deve buscar a superação de análises mecânicas impregnadas de visões ingênuas, metafísicas e acríticas. Esse trato deve levar em consideração a concreticidade - que 
pressupõe analisá-la a partir de sua relação com a realidade social; a criticidade - que subentende a radicalidade, a rigorosidade e a reflexão de conjunto; a objetividade - que requer a explicitação dos fundamentos do modo científico de encarar os fenômenos, como condição para a construção do conhecimento; a especificidade - que envolve o domínio, em amplitude e profundidade do conteúdo em todo o seu conjunto; a flexibilidade - que exige aberturas às contribuições complementares (COLETIVO DE AUTORES, 1992).

\section{A CAPOEIRA COMO UM COMPLEXO TEMÁTICO NO CURRÍCULO DE FORMAÇÃO PROFISSIONAL}

É possível afirmar que o tratamento da capoeira como disciplina curricular surge como uma possibilidade de aproximação da universidade com as chamadas manifestações culturais. Explicitaremos, a seguir, a possibilidade de a capoeira ser tratada no currículo de formação profissional, qualificada pela noção de complexo temático.

Ao se inserir no currículo, como disciplina aplicada, propugnamos que a capoeira deva ser concebida como práxis (capoeirana) e tratada como um complexo temático essencialmente interdisciplinar. Podemos afirmar, baseando-nos em Freitas (2000) e Pistrak (1981), que a capoeira, como complexo temático inserido no currículo de formação profissional, deve levar em consideração a necessária articulação de sua "didática" específica com "didática" geral. A negação de estreitas relações entre conteúdos específicos e processos metodológicos e organizacionais mais amplos contribui para a desarticulação da teoria pedagógica geral.

Segundo Saviani,

ao invés de "especialistas" em determinada habilitação restrita, aquilo de que realmente estamos necessitando é de educadores com uma sólida fundamentação teórica desenvolvida a partir e em função das exigências da ação educativa nas condições brasileiras (2000, p. 61).

A disciplina capoeira, na perspectiva de um complexo temático, deve ser mediada por conhecimento útil, construído em função da transformação da realidade social, com vistas à promoção do homem. E ela somente será útil, se for capaz de contribuir para a formação de 
profissionais com aguda consciência da realidade em que vão atuar, com adequada fundamentação teórica que lhes permitam ações coerentes e consistentes, e com uma satisfatória instrumentalização técnica que lhes possibilitem ações eficazes.

Consideramos que a roda de capoeira, por si só, não garante o esclarecimento e a superação das condições de alienação em que se insere expressivo número de praticantes, evidenciando, desta forma, os limites emancipatórios de uma atividade tratada de forma imediatista, utilitarista, sem uma relação dialética com a totalidade. Saviani (2000, p. 20) nos alerta que nem toda ação pressupõe necessariamente uma reflexão: "Podemos agir sem refletir (embora não nos seja possível agir sem pensar)". Daí a necessidade de desenvolvermos a consciência histórica e a reflexão filosófica para percebermos as necessidades da realidade, pois "quanto mais adequado for o nosso conhecimento da realidade, tanto mais adequados serão os meios de que dispomos para agir sobre ela" (SAVIANI, 2000, p. 58).

Destacaremos, a seguir, os elementos que qualificam o conceito de complexo temático capoeirano, como possibilidade pedagógica para o trato com o conhecimento da capoeira no currículo de formação profissional.

1. O complexo temático capoeirano, ao se articular com outros complexos, como elos de uma mesma corrente, revela as relações reais fundamentais do processo de produção da vida e conduz à compreensão da realidade social. Se, na prática concreta da capoeira intersecionam aspectos psicológicos, políticos, culturais, econômicos da vida em sociedade, ela deve ser experimentada, problematizada, teorizada e reconstruída coletivamente, a partir da análise das condições objetivas de vida dos sujeitos envolvidos, do tipo de trabalho que eles realizam, do que eles se alimentam, como eles cuidam da saúde individual e coletiva, como eles se relacionam com os seus familiares e amigos, o que eles fazem durante o tempo livre e como eles lutam contra a exploração de sua força de trabalho.

2. O complexo temático capoeirano, ao adotar como pressuposto a totalidade concreta, quebra, efetivamente, com as pseudo-hierarquias e estabelece uma relação de ensino-aprendizagem centrada na ação dialógica e não na lógica da ordem, da prescrição, do autoritarismo, muitas vezes velados e sutis, mas, nem por isso, menos perversos 
(KOSIK, 1976). Isso implica no fato de que o mestre (o professor) não precisa de discípulos fiéis e seguidores, mas da inserção fraterna de todos em articuladas redes de intercâmbios em torno de problemáticas significativas da vida, respeitando as características, os acúmulos, as virtudes e limitações de cada integrante do processo educativo, exigindo assim, interatividades múltiplas. É preciso escapar da lógica em que o mestre (o professor) expõe, explica e interroga, e os discípulos escutam, compreendem e respondem, e trabalhar na lógica da auto-organização em que, organicamente, os envolvidos no processo educativo tenham experiências em todas possibilidades do trabalho pedagógico.

3. O complexo temático capoeirano reconhece que na roda de capoeira cada um tem o seu jogo, mas a jogada é coletiva, refuta esquematismos abstratos e opera na lógica da dinamicidade e organicidade da cultura que, por sua vez, pressupõe o exame rigoroso das determinações socioeconômicas sobre os saberes/fazeres desta cultura e a articulação de procedimentos pedagógicos, para a superação de estágios de compreensão do senso comum, a partir de aportes teóricos explicativos, articulados entre si, e construídos a partir de reflexões dialogicamente mediadas sobre o cotidiano da capoeira e intermediadas por formas ativas e criativas de produção de conhecimento sobre a temática.

4. O complexo temático capoeirano trata a história da capoeira na sua essência dinâmica. Com isso, evita a sua idealização e a sua mitificação, contribuindo, desta forma, para que seus praticantes não se sintam alheios ao passado ao qual estão vinculados, mas sim, como partícipes de um presente histórico. Esta questão é de importância crucial à medida que, via de regra, se verifica uma compreensão reduzida da história da capoeira, expressa por uma preocupação meramente biográfica, em que muitos acreditam que conhecer a história da capoeira é saber o nome de alguns mestres consagrados e os seus dados cronológicos.

5. O complexo temático capoeirano articula, de forma equilibrada, diferentes possibilidades metodológicas para fazer frente ao alto grau de complexidade da cultura da capoeira, em busca de fundamentações conceituais e instrumentais que possibilitem uma leitura/ análise sem sectarismos em relação a esta manifestação, fazendo 
com que, dialeticamente, a teoria aponte caminhos e seja, igualmente, reconstruída pela prática, alçada ao nível da consciência filosófica.

6. O complexo temático capoeirano reconhece que a capoeira constitui uma síntese de múltiplas determinações em jogo. Esse jogo exige intercâmbio, participação ativa e diálogo constante para se atingir não um conhecimento qualquer, prescrito pelo mestre ou professor, mas um conhecimento extraído da prática social, necessário à transformação da realidade e à superação do modelo societal hegemônico.

\section{CONSIDERAÇÕES FINAIS}

Mesmo que o conceito de complexo temático possa sugerir um campo infinito de possibilidades, o complexo temático capoeirano não deve ser confundido com um ecletismo cômodo ou um hibridismo conciliador. Ela deve "jogar" com conceitos mais elásticos, sem, no entanto, perder-se em generalizações vagas e apressadas, ou lugares-comuns, que apenas servem para legitimar doutrinas hegemônicas.

Por fim, conforme foi explanado, a experiência histórica da capoeira é conflituosa, densa, dinâmica e contraditória. Embora tenha se tornado refém, como mercadoria, dos interesses do capital, consolidou, no calor das contradições do seu desenvolvimento histórico, saberes significativos que, se forem referenciados pela noção de complexo temático, podem contribuir efetivamente para o desenvolvimento da prática pedagógica numa perspectiva autodeterminada, autônoma, solidária, reflexiva e crítica.

Beyond the prescribing methodologies in physical education: The possibility of capoeira as a thematic complex in the curriculum of professional formation.

\section{ABSTRACT}

This article aims at critiquing the alienating character of the so-called "prescriptive methodologies" in the field of physical education in Brazil and it presents, as a reference and counterpoint, some aspects from the development of capoeira and the possibility of dealing with this knowledge from the notion of theme complex.

KEY-WORDS: education - physical education - capoeira - pedagogical practices dealing with knowledge. 
Más allá de las metodologías prescriptivas en Educación Física: la posibilidad de la capoeira como complejo temático en el currículo de formación profesional.

\section{RESUMEN}

Este artículo tiene por objetivo criticar el carácter alienador de las denominadas "metodologías prescriptivas" en el campo de la Educación Física brasileña y presenta, como referencia, aspectos de desarrollo de la capoeira y la posibilidad de trato con ese conocimiento a partir de la noción de complejo temático.

PALABRAS-CLAVES: educación - educación física - capoeira - práctica pedagógica trato con el conocimiento.

\section{NOTAS}

1 Segundo Almeida (1982), inicialmente, o exame de admissão de Mestre Bimba consistia no "teste da gravata" que exigia do candidato à capoeira, resistir por três minutos, "sem chiar", a uma gravata aplicada no seu pescoço pelo próprio Mestre, que era "pra ver se o cabra era homem". Se agüentasse, estaria aprovado, poderia matricular-se no "Centro de Cultura Física e Regional" e começar os treinamentos. Posteriormente, Mestre Bimba passou a utilizar uma seleção biotipológica que exigia resistência física e flexibilidade, ou "junta mole", como ele dizia. O pretendente teria que demonstrar alguns movimentos como a "cocorinha" (esquiva que consiste num agachamento com uma das mãos no chão), a "queda de rins" (exercício de equilíbrio de cabeça para baixo, em que o capoeira se apóia nos cotovelos e coloca a cabeça no chão) e a "ponte", que é conhecida como reversão na ginástica olímpica.

2 O "Esquenta Banho" consistia num jogo mais duro, que ocorria após os treinamentos formais, quando os alunos se preparavam para tomar banho. Para não esfriar o corpo, os alunos mais velhos, normalmente os formados, tomavam a iniciativa e começavam o "Esquenta Banho", desafiando dois ou três adversários ao mesmo tempo. Segundo Mestre Decanio, "este era um momento fértil da aula, pois se tratava do espaço do aluno, também chamado de 'Bumba Meu Boi' ou 'Arranca Rabo', devido aos freqüentes desafios para o acerto de contas, como exemplo, descontar um golpe tomado durante a roda" (DECANIO FILHO, 2002, p. 3). Esse nome é decorrente do fato de que a academia do Mestre possuía apenas um banheiro e, por isso, os alunos ficavam jogando para se manterem aquecidos, "esquentando para o banho" (ALMEIDA, 1994, p. 79). 
3 A "cintura desprezada" consiste numa série de projeções (golpes ligados em que se procura agarrar o adversário e projetá-lo ao chão, geralmente por cima do próprio corpo) e também é chamada de "balões cinturados".

4 A chamada é um dos rituais mais característicos da Capoeira Angola e consiste, sinteticamente, em um momento do jogo em que um capoeira pára em pé, de frente ou de costas para o outro jogador, com os braços abertos. O outro jogador deve "responder" à chamada aproximando-se, cuidadosamente, para não ser surpreendido porque o capoeira que chama poderá aplicar o golpe que desejar, caso o outro se aproxime sem o devido cuidado. Ao se encontrarem, ambos fazem deslocamentos sinuosos e matreiros para frente e para trás.

\section{REFERÊNCIAS}

ALMEIDA, R. C. A. Bimba: perfil do mestre. Salvador: Centro Editorial e Didático da UFBA, 1982. eira, 1994.

A saga do Mestre Bimba. Salvador: Ginga Associação de Capo-

BURLAMAQUI, A. Gymnastica nacional (capoeiragem): methodisada e regrada. Rio de Janeiro: o autor, 1928.

CARNEIRO, E. Capoeira. 2. ed. Rio de Janeiro: INAP/FUNARTE/ SEC/MEC, 1977.

COELHO NETO. O nosso jogo. In: Bazar. Porto: Livraria Chardron, 1928.

COLETIVO DE AUTORES. Metodologia do ensino de Educação Física. São Paulo: Cortez, 1992.

CUNHA, R. C. O. A crise de legitimação da concepção crítica de currículo. Tese (Doutorado em Educação). Rio de Janeiro, Faculdade de Educação, Universidade Federal do Rio de Janeiro, 1997.

DECANIO FILHO, A. A. Capoeira regional. Disponível em $<$ http:// www.geocities.com>. Acesso em 30 nov. 2002.

FREITAS, L. C. Crítica da organização do trabalho pedagógico e da didática. 3. ed. Campinas, SP: Papirus, 2000. 
HOBSBAWM, E. A era dos extremos: o breve século XX (19141991). São Paulo: Companhia das Letras, 1995.

KOSIK, K. Dialética do concreto. Rio de Janeiro: Paz e Terra, 1976.

MARINHO, I. P. Subsídios para o estudo da metodologia do treinamento da capoeiragem. Rio de Janeiro: Imprensa Nacional, 1945.

MORAES FILHO, M. Capoeiragem e capoeiras célebres. In: Festas e tradições populares. São Paulo: EUSP/Itatiaia, 1979.

MOREIRA, A. F. B. A crise da teoria curricular crítica. In: COSTA, M. V. O currículo nos limiares do contemporâneo. 2. ed. Rio de Janeiro: DP\&A, 1999.

O. D. C. Guia do capoeira ou gymnastica brazileira. 2. ed. Rio de Janeiro: Livraria Nacional, 1907.

PIRES, A. L. C. S. Bimba, Pastinha e Besouro de Mangangá: três personagens da capoeira baiana. Tocantins/Goiânia: NEAB/Grafset, 2002.

PISTRAK. M. M. Fundamentos da escola do trabalho. São Paulo: Brasiliense, 1981.

SANTANA, J. Velhos mestres. Correio da Bahia. Salvador: Caderno Correio Repórter, p. 1-7, 15 abr. 2001.

SAVIANI, D. Educação: do senso comum à consciência filosófica. 13. ed. Campinas: Autores Associados, 2000.

VIEIRA, L. R. O jogo de capoeira: cultura popular no Brasil. Rio de Janeiro: Sprint, 1995.

Recebido: 30 de abril 2004

Aprovado: junho de 2004

Endereço para correspondência

Servidão das Vassouras, n. 65

Canto da Lagoa - Florianópolis - SC

88062-272

E-mail: falcaox@cds.ufsc.br

170 FALCÃO, J. L. C. Para além das metodologias prescritivas na educação ... 